\title{
Sesenta años del cuento mexicano de temática gay
}

\author{
León Guillermo Gutiérrez \\ Universidad Autónoma del Estado de Morelos
}

\begin{abstract}
RESUMEN
El presente artículo lleva a cabo una revisión de la heterogeneidad de la estética y técnica con que se aborda el tema gay en sesenta años de su escritura, a partir del inicio de la segunda mitad del siglo XX, hasta el día de hoy. El tema es tratado desde muy diversos ángulos y con perspectivas que van de la aventura jocosa, hasta la más intrincada perversión, pasando por la ternura, etc.; todo ello la particular perspicacia de los autores.
\end{abstract}

Palabras clave: literatura homoerótica, cuento, México.

\section{Sixty years of the Mexican story of gay subject matter}

\begin{abstract}
The present article carries out a review of the heterogeneity of the aesthetics and technology with which the gay topic is approached in sixty years of his writing, from the beginning of the second half of the 20th century, until today. The topic is treated from very diverse angles and with perspectives that go of the jocular adventure, up to the densest perversion, happening for the tenderness, etc.; all this the particular perspicacity of the authors.
\end{abstract}

Key words: Literature homoerótica, short storie, México.

Y arriesgado es besarse y oprimirse las manos, ni siquiera mirarse demasiado, ni siquiera callar en buena lid... Carlos Pellicer

Por desgracia o por historia, una palabra define a México en todos los aspectos: atraso. José Emilio Pacheco, al hablar de las diferencias del naturalismo en Europa y América, establece que mientras en el viejo continente esta corriente literaria corresponde a un esplendor industrial y económico, en los países hispanoamericanos, anuncia el comienzo del subdesarrollo. En la literatura cuyo discurso es el homoerótico, México no sólo queda rezagado de Europa sino del mismo continente americano. En Brasil, a finales del siglo XIX, se publica Bom Criollo (1895), de Adolfo Caminha; en Cuba se publican entre otras obras, El Ángel de Sodoma 
(1928), de Alfonso Hernández Catá, La vida manda (1929), de Ofelia Rodríguez Acosta y Hombres sin mujer (1938), de Carlos Montenegro. Los autores del continente que han incursionado en el tema son numerosos: José Donoso, José María Arguedas, Manuel Ramos Otero, Augusto D'Halmar, Isaac Chocrón y Manuel Mújica Lainez. Eso sin tomar en cuenta los últimos treinta años en que la temática gay ha sido abordada de manera prolífera en toda América. El caso de México es singular: la primera novela de argumentación totalmente homosexual data de 1964 con la aparición de El diario de José Toledo, de Barbachano Ponce, que sigue en el olvido editorial y del análisis crítico. Retomando las palabras de Pacheco, el subdesarrollo de México no fue sólo un anuncio, es y sigue siendo una realidad irrefutable.

A lo largo del siglo XIX, en México se luchó con esmero para preservar la cultura, las costumbres y los valores criollos. La literatura decimonónica ayudó a fijar los modelos europeos como los estereotipos de la clase media y la burguesía. De ello dan cuenta las novelas de Fernández de Lizardi, Ignacio Manuel Altamirano, Rafael Delgado, entre muchos más. En el siglo XX, los gobiernos posrevolucionarios dictaron la pauta a seguir: una política nacionalista de un machismo exacerbado. El resultado de la ecuación es simple: las normas y conductas de vidas públicas y privadas son regidas por los valores impuestos desde el poder político, económico y religioso. Es por eso que en México el tema de las relaciones homoeróticas queda inscrito dentro de las prácticas más satanizadas. De ahí que los escritores hayan mantenido reserva y distancia ante un asunto que pudiera dañar su imagen.

En este trabajo se hace una revisión de la heterogeneidad de la estética y técnica con que se aborda el tema gay en sesenta años de su escritura, a partir del inicio de la segunda mitad del siglo XX, hasta el día de hoy. El mismo tema (de por sí restringido) es tratado desde muy diversos ángulos y con perspectivas que van de la aventura jocosa, hasta la más intrincada perversión, pasando por la ternura, la fineza intelectual, la sordidez, la prostitución, el refugio del arte, el cinismo, la fechoría, la complicidad, la enfermedad terrible; todo ello condimentado bajo el signo de Eros y la particular perspicacia de los autores.

Por todos es sabido que la novela de la Revolución abarcó y acaparó la atención por más de medio siglo. Hasta 1940, México estuvo gobernado por regímenes militares, y la literatura, hasta entrados los años cincuenta, estuvo permeada por el tema de la gesta revolucionaria. Aunque la homosexualidad y su práctica siempre han existido, su permisividad no ha sido equivalente. Los valores seculares y los prejuicios de la Iglesia católica, hacían del tema un verdadero tabú que atacaba los principios del devoto cristiano de doble moral y más aún los atributos de gallardía del charro, figura emblemática del mexicano. Será la década de los años cincuenta en que se inicie un cambio de rumbo, con la aparición de libros de cuentos que harán del género un verdadero crisol de la nueva literatura, como ejemplo destacan: Los días enmascarados (1954), de Carlos Fuentes; Confabulario (1952) y Bestiario (1959), de Juan José Arreola; El llano en llamas (1953), de Juan Rulfo; y Tiempo 
destrozado (1959), de Amparo Dávila. Con estos escritores a la cabeza, el cuento cobrará una inusitada revaloración y auge en las siguientes décadas.

El primer relato del que tenemos noticias que trata el tema homosexual, aunque de manera soslayada, es "Los machos cabríos", de Jorge Ferretis, publicado en 1952. El cuento, narrado de forma impecable, no ofrece mayor complicación en su estructura, es una historia lineal; es la historia de Filemón, quien llega a vivir a un vecindario y es descrito por el narrador como: "un hombre ancho, carnoso. Casi no tiene barba $\mathrm{y}$, sin embargo, sus bigotes brotan gruesos, como arranque de trenzas...se le enroscan como anillos para dedo pulgar...su voz es delgaducha, como si dentro llevase un hombrecillo enjuto, mínimo y demasiado jovial." (24) Descripción que habrá de complementarse con la percepción que otros personajes tendrán del protagonista en relación a sus actitudes. Por ejemplo, la portera se percatará que el motivo que retiene a Filemón en la vecindad no es la falta de recursos económicos, sino su gusto por jugar y cuidar de los niños, lo que ocasionará que digan que: "Es más apto para las labores del hogar" (25); lo que le valdrá el mote de Don Marica. A todas luces el protagonista del cuento de Ferretis es un hombre con características feminoides, y el apodo alude a una orientación homosexual, sin que el personaje llegue a concretar ninguna conducta homoerótica. Aquí cobra validez la tesis de Ricardo Piglia cuando dice que: "La historia secreta es la clave de la forma del cuento y sus variantes. La historia secreta se construye con lo no dicho, con el sobreentendido y la alusión." (108) El cuento, con lo no dicho, retrata el momento histórico (la última fase de la década de los años cuarenta) de una sociedad cada día más industrializada y urbana y más propicia para el anonimato, donde la visibilidad del gay es más notoria, pero: "Para el Estado y sus instituciones de la década de 1940 poco a nada importa como se definieran o quisieran hacerlo, porque para ellos eran o 'monstruos' o 'enfermos.' Lo que nos sugiere que en los cuarenta siguió creciendo el debate de la homosexualidad en términos académicos o científicos." (Palma, 100) La narración de Ferretis, en un momento dado, convierte al personaje en objeto de la medicina, a quien un médico principiante pretende realizar un injerto para que: "pudiesen corregir su condición humana." (30) Lo que conlleva el sobreentendido y la alusión a la homosexualidad nunca mencionada de Filemón. Entonces la historia secreta que se entreteje es la "enfermedad" del homoerotismo del personaje. Aquí cabe mencionar que en el año de 1948, Alfred C. Kinsey, publicó El comportamiento sexual en el hombre, basado en 18,000 entrevistas, que arrojaron, entre otras conclusiones, que el $37 \%$ de los hombres entrevistados experimentaron alguna vez un orgasmo homosexual a partir de la adolescencia, y que la mitad de los varones de la muestra estudiada habían tenido al menos una experiencia homosexual (a nivel físico o de fantasía), y que la homosexualidad existía en todos los niveles sociales y ocupacionales.

En 1964 Barbachano Ponce publica El diario de José Toledo, escrita a finales de los años cincuenta, y por ella sabemos que la práctica sexual entre hombres era parte de la vida cotidiana y con una mayor desenvoltura. Varios de los personajes 
dan cuenta de la agitada vida gay existente y manifiesta en calles, parques, cantinas, cines. Si bien la novela está permeada por la tragedia, también es cierto que es una historia de amor, lo que prueba que el homoerotismo en esa época no estaba sólo circunscrito a encuentros sexuales clandestinos y pasajeros, sino que el afecto y las emociones involucraban una relación de mayor intimidad y compromiso. No obstante:

La nota roja de los cincuenta empieza a registrar frecuentemente noticias de los "homosexuales", se van difundiendo imágenes de homosexuales afeminados y las representaciones sociales se presentan como las de tipos con vida sórdida, asociados a la delincuencia, a la inseguridad pública. (Palma, 107)

El desenfreno, la libertad sexual, la vitalidad juvenil que se vive en la década de los sesenta, el resquebrajamiento de la figura altiva y bravía de la conjunción del militar con el charro, convertida ahora en una masculinidad andrógina de ajustados pantalones y largas cabelleras que bailan y cantan al ritmo del rock and roll, y también una mayor visibilidad del gay, no se incorpora a la cuentística de esta temática. Aquí cobra validez lo señalado por Luis Mario Schneider:

Es demostrable que la creación estética individual está sujeta a condiciones de presión social. La moral, la ética creadora, identidad de la humanidad del individuo que la ejerce, conlleva una timidez supeditada a la comprensión general, mejor, la aceptación cívica porque en última instancia la imposición de nuevas formas de vida es siempre una problemática educacional. (70)

Carlos Fuentes es uno de los pioneros al abordar el tema en: "A la víbora de la mar" (1964), un relato más cercano a la novela corta, donde al final se descubre la relación homoerótica. Por fortuna, a esta década pertenece el cuento: "Los amigos" (1962), de Juan Vicente Melo. El relato privilegia el espacio como organizador narrativo, y es que:

El espacio es con frecuencia prolongación metonímica de los personajes, que la mirada de éstos es uno de los recursos más corrientes para la inserción descriptiva y que toda presencia espacial, por culpa de su sobrecarga semántica, inevitablemente se trasciende así misma y se hace metalingüística. (Zubiaurre, 24)

La ciudad, las calles, jardines, iglesias, edificios, automóviles, ruidos, dotan de un gran movimiento, mientras que Enrique se encuentra estático frente a la ventana de Andrés, y a lo largo de la historia se encuentra sumido en sus pensamientos y memoria. En una prosa ágil, elegante y de extraordinaria riqueza verbal, las acciones avanzan, se detienen, retroceden, se repiten, en una estructura narrativa que apela a un lector que reconstruya la fragmentación de acciones, tiempos y espacios. 
La amistad de los dos jóvenes, cargada de un sutil homoerotismo, es descrita por la única voz narrativa en tercera persona:

Sentía el brazo de Andrés apretado al suyo, el pecho subiendo y bajando con calma, el calor obediente al ritmo de la respiración. El aire se llenaba de la presencia de ellos, de un momento distinto, un chasquido de lengua, un alzar de hombros o una risa que no tenía antes el aire. (Melo, 38)

Después de una relación amistosa de cerca de cuatro meses, uno de ellos, Andrés, se suicida sin que se sepan los motivos, lo que origina que Enrique vuelva una y otra vez a los recuerdos incesantes, a la memoria fija en la fotografía donde aparece muerto Andrés con un solo ojo abierto, y a la incertidumbre y desasosiego de ser implicado. La tragedia de uno de los protagonistas en relatos de este tema es bastante común, es parte de una cultura basada en la culpa y el remordimiento, en que la prohibición de felicidad es tácita para quienes ostentan una orientación sexual al margen de la normatividad social impuesta.

La década de los setenta está marcada por el llamado "Boom Latinoamericano", tres años antes, 1967, García Márquez publica Cien años de soledad, el libro máximo de este movimiento. La nueva literatura que se impone manifiesta su preocupación por el desarrollo de estructuras narrativas que exigen un lector activo; la experimentación lingüística es otra de sus características; se presenta la insistencia de plantear la propia creación literaria como tema; cobra importancia lo históricosocial y hay un rechazo hacia la moral burguesa; y sobre todo se ensaya una gran variedad de fórmulas narrativas, donde es frecuente la ruptura de la línea argumental. Es importante destacar que esta renovación da como resultado una literatura que equilibra la creación estética con el compromiso social y la denuncia histórica. El cuento es uno de los géneros más beneficiados, con Borges a la cabeza. Si bien es cierto que la novela se impone, el cuento cobra un valor y un vigor nunca antes visto y es colocado en un sitio de primerísimo orden. A ello contribuyen autores de la talla de Julio Cortázar, Juan Carlos Onneti, Carlos Fuentes, entre otros, que van a influir de manera decisiva en la transformación de la cuentística de las nuevas generaciones.

Los setenta son años de cambios radicales. En México se da una permisividad encubierta a las prácticas homosexuales, se abren bares, se organizan movimientos libertarios y contestarios y el tema comienza a ser parte del debate político. También es el momento en que, como parte de la construcción de identidad del sujeto homoerótico, se adopta el término gay que desplaza a los demás motes peyorativos, y a la misma palabra "homosexual", por considerar que esta última enfatiza de manera desproporcionada el acto sexual, excluyendo y deshumanizando las relaciones afectivas entre hombres. Por mala fortuna, los nuevos vientos de libertad sexual y renovación literaria no se van a reflejar en la cuentística mexicana de tema gay. En el género de la novela, El Vampiro de la Colonia Roma (1979), de Luis Zapata, de 
manera abrupta irrumpe y arroja sobre la doble moral de la sociedad mexicana la visibilidad de lo que se esmeraba por ocultar en el rincón del clóset: la práctica cotidiana de la homosexualidad en todas las esferas sociales. Zapata no se conforma con sacarla del armario, la lleva y la pasea a pie, en auto, en autobús o motocicleta por calles, avenidas, parques, restaurantes y cines de la gran ciudad y otras latitudes de la geografía del país.

Sólo tres relatos cubren esta década, "Mapache" (1975), de Arturo Ojeda, "Los zapatos de la princesa" (1978), de Guillermo Samperio, y "Siete veces el sueño" (1979), de Luis Arturo Ramos. Los dos cuentos son sumamente breves, así que no se propicia ni el desarrollo ni la profundidad. Son escritos bajo los signos de la nueva modernidad de la estética literaria. Mientras en el primer cuento el argumento es un deseo inconfesado, que en las últimas líneas se descubre y es el que el narradorpersonaje siente por su cuñado; en el segundo, el número siete como fórmula cabalística se presenta en un sueño imposible de recordar, pero que deja sus huellas en las marcas violáceas de los hombros como mordiscos recién dados. Los dos protagonistas saben que de nuevo vendría el sueño donde ambos soñarían lo mismo, y a la mañana sería imposible su recuerdo, sólo quedarían las marcas en los hombros. Los dos textos tienen gran similitud, el discurso homoerótico queda anulado. Los deseos y los sueños homosexuales deben ser borrados, como si no existieran. El afecto y el erotismo por otro hombre son sólo sugeridos, aunque en la realidad las marcas y el dolor digan lo contrario. Porque como dice Michel Foucault: "La sexualidad nunca ha tenido un sentido más inmediatamente natural y sin duda nunca ha conocido una 'felicidad de expresión' tan grande como en el mundo cristiano del pecado y los cuerpos desposeídos de la gracia divina." (1)

En la década de los ochenta, la literatura latinoamericana está consolidada y reconocida a nivel mundial. Circulan por todo el continente las obras de Bioy Casares, Álvaro Mutis, José Donoso, Octavio Paz, Alejo Carpentier, Alfredo Bryce Echenique, Juan Rulfo, José Lezama Lima, Guillermo Cabrera Infante, Manuel Puig, Mario Benedetti, Augusto Roa Bastos, Mario Vargas Llosa y, los anteriormente citados, Borges, Fuentes, Cortázar y Onneti. Por primera vez tienen amplia difusión novelas de tema homoerótico: El beso de la mujer araña (1966), de Manuel Puig; El lugar sin límites (1977), de José Donoso; El Divino (1985), de Gustavo Álvarez Gardeazábal; Otra vez el mar (1982), de Reinaldo Arenas, entre otras. Es cierto que el Premio Nobel de literatura es un reconocimiento de carácter individual; en 1982, al concederse a Gabriel García Márquez, hay una velada y sutil distinción a la literatura del continente que ya dejaba grandes dividendos a las editoriales trasnacionales. En México, el tema gay se escribe con mayor profusión. En la novelística se publican: Octavio (1982), de Jorge Arturo Ojeda; Melodrama (1983), En Jirones (1985), y La hermana secreta de Angélica María (1989), de Luis Zapata; Sobre esta piedra (1982), de Eduardo Turón; Utopía Gay (1983), de José Rafael Calva; y Las púberes canéforas (1983), de José Joaquín Blanco. En el género del cuento incursionan autores de diversas generaciones, pero todos con la misma in- 
tención: hacer manifiesta en la literatura que las relaciones homoeróticas son una realidad que permea en todos los estratos sociales. Para ese entonces, la década de los ochenta, la cultura gay es un hecho. En la academia norteamericana y europea el tema comienza a ser objeto de estudio. En México, y más propiamente dicho en la ciudad de México, la clase media gay vive una mayor libertad, su visibilidad se ve legitimada por los mismos medios de comunicación, se inicia el desplazamiento de sordidez a la que era asociada la práctica sexual entre hombres; la focalización erótica disminuye ante la evidencia de la construcción de las relaciones afectivas que dan un giro a la identidad del sujeto gay; prolifera la apertura de discotecas, bares, restaurantes y comercios propicios para la reunión y encuentro para gays:

En la ciudad de México aparecen espacios y discursos alternativos sobre la SMS (Sexualidad del Mismo Sexo). Éstos provocan un impacto cultural en el orden de género. Los espacios urbanos van siendo reapropiados, como en el caso de la colonia Roma o la colonia Juárez, la para entonces turística y elitista Zona Rosa. (Palma, 118)

Durante la década de los ochenta no hay una proliferación en el cultivo del cuento de temática gay, pero crece el número. Se publican "Doña Herlinda y su hijo" (1980), de Jorge López Páez; "El vino de los bravos" (1981), de Luis González de Alba; "Respiración artificial" (1982), de Raúl Hernández Viveros; "Todos somos vecinos" (1982), de Dolores Plaza; "Ríos que vienen del mar" (1983), de Antonio Argudín; "Un caso semejante" (1983), de Agustín Monsreal; "De amor es mi negra pena" (1983), de Luis Zapata; "El hábito oculto" (1984), de Ignacio Betancourt; "Juego de ajedrez" (1984), de Fidencio González Montes; "También hay inviernos fértiles" (1986), de Severino Salazar; y "Opus 123” (1988), de Inés Arredondo.

Jorge López Páez (Huatusco, 1922), quien ya había incursionado en el tema y el género en 1962 con "El viaje de Berenice", en 1980 publica en el suplemento Sábado, del periódico Unomásuno, "Doña Herlinda y su hijo". Con esto se convierte en el primer relato de tema gay de amplia difusión, siendo tal el impacto que es llevado al cine bajo la dirección de Jaime Humberto Hermosillo en 1984. En la película intervienen Manuel Barbachano Ponce como productor, y el ahora internacionalmente conocido director de cine, Guillermo del Toro, como productor ejecutivo; también cuenta con la participación de Lucha Villa. La película y el cuento de inmediato acapararon la atención de estudiosos norteamericanos y se han convertido en motivo de análisis e inclusión obligada en los estudios críticos, baste mencionar que ocupa todo un capítulo del importante libro: Sexo y sexualidad en América Latina (1997), de Daniel Balderston.

El relato, de aparente desaliño, pretende hacer del texto una narración oral, cuyo discurso está a cargo de la voz del joven protagonista en un lenguaje directo, coloquial, en una sintaxis de oralidad llana. El cuento toma préstamos de la farsa por la exageración, así como de la comedia donde los protagonistas después de vencer 
obstáculos de la vida cotidiana tienen un desenlace feliz y se hace escarnio de la debilidad humana. Es la voz del narrador-protagonista, que de manera progresiva cuenta su historia, la que está íntimamente ligada a los demás personajes, y cuyo peso mayor recae en doña Herlinda, madre de Rodolfo, su amante. La madre, al tanto de la relación homoerótica de su hijo médico con Moncho, estudiante de música, en lugar de oponerse, se convierte en la aliada incondicional, pero desde la hipocresía. La complicidad tiene como objeto no romper con la estructura machista y conservadora de la sociedad tapatía. Con sagacidad doña Herlinda auspicia no sólo que Moncho viva con ellos, sino que lo invita a compartir la cama del hijo: "Es tan grande que con toda comodidad pasarán la noche." (López Páez, 80) Rodolfo, para "complacer" a su madre y permitirle que siga en su papel de partícipe, se compromete en matrimonio con Olga, formando un cuarteto perfecto en las salidas de los domingos: Olga y Rodolfo, doña Herlinda y Moncho. Al acercarse la fecha del enlace de la pareja, doña Herlinda, que nota la preocupación del joven, le dice: "Moncho, usted no se preocupe. Le digo, no se achicopale. Yo me las arreglaré". (83) La boda se celebra siendo Moncho testigo principal en el rito civil, y padrino en el religioso. En el poco tiempo que los desposados viven en un departamento, doña Herlinda fomenta y ayuda para que Moncho y su hijo tengan encuentros los martes y los viernes, mientras ella lleva a Olga al cine. Antoine Rodríguez, en su ensayo: "El joto decente se casa. Normas y margen en Doña Herlinda y su hijo", escribe:

Doña Herlinda y su hijo presenta dos conjuntos, el de las normas visibles de la heterosexualidad y el del margen invisible de la homosexualidad que, en vez de excluirse como suele pasar, pactan tácitamente un acuerdo a través del cual el primero encubre y silencia al segundo. (S/D)

Antes del nacimiento del primer hijo ya viven en la casa de la madre, quien martes y jueves propicia el encuentro de los amantes, y cuando está en camino el tercer hijo para que no se complique la situación construye encima del garage un pequeño departamento con doble salida para Moncho. El narrador da fin a su historia: "vivo con una familia extraordinaria, de la que no puedo prescindir." (85) El relato en sí, es una muestra de la doble moral imperante, y que sin llegar a ser explícito toda una sociedad conviene en las relaciones homoeróricas, siempre y cuando se guarden debidamente las apariencias y no se ponga en riesgo la respetabilidad y las buenas costumbres de la burguesía. Si bien es cierto que es obvia la relación erótica que mantienen los dos hombres, también lo es que está encubierta no sólo por la madre sino por la esposa. El fingimiento, el ocultamiento y la hipocresía hacen patente la prohibición de transgredir las normas sociales y religiosas de la sociedad que aquí se representa. Como señala Bataille: "En todas las épocas, como en todos los lugares -en la medida que tenemos información al respecto-, el hombre se define por una conducta sexual sometida a reglas, a restricciones definidas." (54) A lo largo 
del relato, el discurso homoerótico queda en un segundo plano, queda de cierto modo aplastado por la madre, quien impone su voluntad y figura a través del "permiso" que le otorga al hijo como recompensa por cumplir con su rol de macho ante la vista pública. Bien señala Rodríguez:

No reivindica explícitamente una postura ideológica o teórica acerca de la liberación gay. Su compromiso es otro: exhibe lo que la decencia clasemediera sólo puede aceptar silenciándolo, muestra cómo las normas heterosexuales engullen toda conducta marginal y deconstruye hábilmente, los tópicos que desgraciadamente han nutrido -y siguen nutriendo- el imaginario colectivo acerca de las relaciones homoeróticas masculinas. (S/D)

Luis González de Alba, uno de los líderes del movimiento estudiantil del 68, autor de Los días y los años (1971), en "El vino de los bravos" (1981) recrea una hipérbole orgiástica entre hombres hermosos y viriles; que es quizás el reflejo, por una parte, de la contención homoerótica en México y, por la otra, la realidad de promiscuidad que se vivía en lugares como San Francisco y Nueva York, principalmente; lo que infiere una amplia red de relaciones homosexuales de gran visibilidad en Estados Unidos. En el relato no hay lugar a pausas, la estructura es la simultaneidad del tiempo y el espacio, la acción está determinada por la masturbación de Rodrigo dentro de un carro en Las Ramblas de Barcelona, a vista de todos, mientras su imaginación nos conduce a Venecia, Ámsterdam, Monterrey, Atenas, Roma, Cozumel, Sao Paulo. La belleza masculina no hace distinción de mulatos, negros, rubios y morenos: "Los de los brazos perfectos, los de piernas de gladiador, los de hombros poderosos que bajan en triángulo hasta la cintura firme, los de nalgas pequeñas y duras como duraznos." (González, 183) Sin concesiones, el ambiente está impregnado de un homoerotismo donde el gozo sexual no da pie a la inhibición. Los encuentros bien pueden darse en bares, saunas, cines, estaciones del ferrocarril y ser múltiples los participantes sin que haya frenos de por medio. Como señala Bataille: "En la orgía, los impulsos festivos adquieren esa fuerza desbordante que lleva en general a la negación de cualquier límite. No era por azar que en las orgías saturnales se invertía el orden social mismo, con el amo sirviendo al esclavo y éste acostado en el lecho de aquél." (118)

Ceñido a los modelos griegos, el esteticismo se da cita en la magnificación del encanto masculino. En las imágenes que también pueden ser oníricas, el protagonista entra a Central Park y camina por Chapultepec; atraviesa un callejón de Brooklyn cercano a la Merced. No obstante el discurso es uno: el espacio del cuerpo como proveedor de placer erótico, dando también lugar a la cosificación, pues en esta gran orgía el afecto y las emociones quedan anuladas.

Las posibilidades y vertientes de la homosexualidad son muy diversas y de gran complejidad. Así como existen las relaciones de igualdad entre hombres del mismo sexo, también es cierto que las sombras y la oscuridad se ciernen sobre algunas 
prácticas condenables bajo cualquier circunstancia, como son los temas que trata el cuento de Raúl Hernández Viveros: "Respiración artificial" (1982), donde se dan cita la pedofilia, la violación, la muerte y la impunidad. En un breve relato de estructura convencional ambientado en el puerto de Veracruz, un capitán de barco, de nacionalidad americana, comete el brutal crimen en contra de un niño que encuentra solo y llorando debajo de una banca en el malecón. Es en el camarote de la nave donde se lleva a cabo la estrujante infamia. El cuento coloca bajo la luz una de las prácticas sexuales que más se pretenden ocultar, y que por desgracia se realizan con frecuencia, a veces, bajo el amparo de la figura de poder del pederasta, como ha sido la conducta de sacerdotes, y que en los últimos años la prensa internacional se ha ocupado ampliamente de este sórdido y escandaloso pasaje de la Iglesia católica.

Dolores Plaza, "En Todos somos vecinos" (1982), pone al descubierto el erotismo entre hombres de baja condición social y económica en una atmósfera de clandestinidad y, quizás por ello, de mayor excitación. El espacio denota lo secreto y lo prohibido: el zaguán, las escaleras, la oscuridad. El encuentro se da en: "Un cuarto inmundo, con una larga mesa de carpintería, una estufa de petróleo y una cama harapienta. Sobre la cama colgaba un almanaque del año anterior, con Brigitte Bardot desnuda, comiéndose una manzana." (121) El protagonista, un jovencito de quince años, huérfano, hijo de españoles, no sólo no opone resistencia ante el pulquero maduro, casado y con hijos que lo quiere "adoptar", sino que goza el acto sexual que es descrito de manera explícita, sin tapujos, al igual que el lenguaje directo y llano de los diálogos:

Me metió en el culo su verga limpia, y me zarandeó lastimándome con sus manazas las costillas, hasta que eyaculó, mitad en mí y mitad en las harapientas sábanas del compadre. Yo tenía escaldado el ano, y me dolió. Pero luego volvió a fijarse en mi instrumento, y lo lamió y lo acarició con sus bigotes. (122)

Aquí la sexualidad carece de etiquetas debido a que, en muchos casos, en las clases proletarias los estigmas y la moral burguesa no los alcanza. El joven lo único que pretende es irse a la capital con su amante El Gato, otro hombre casado que trabaja en la pulquería de su suegra. En el relato las descripciones, las acciones y los diálogos funcionan en un entretejido que da como resultado un discurso homoerótico de gran tensión, sin enjuiciamientos, sin culpas; la naturalidad sexual y el placer son el argumento.

Luis Zapata, autor de El vampiro de la colonia Roma (1979), la novela de temática gay de mayor importancia en México hasta el día hoy, muestra también sus dotes de gran narrador en el cuento "De amor es mi negra pena" (1983). En el relato, dividido en cuatro capítulos, mismos en los que la focalización del narrador va cambiando, la trama se corresponde con la intensidad y la perspectiva narratológica que va adquiriendo la historia. Reunidos alrededor de una mesa jugando y tomado cervezas, un grupo de soldados se encuentran a la expectativa del partido de futbol 
que enfrentarán el día siguiente. Las primeras palabras con las que abre el texto caen abruptas: "Ha de ser puto", (Zapata, 29) La especulación afirmativa de que uno de los amigos es homosexual, encierra en sí misma una codificación peyorativa y degradante en un ambiente social donde ser "puto" es no ser hombre. El relato, más cercano al hiperrealismo, en una estructura narrativa que pudiera llamarse en tercera dimensión, recrea una escena donde la escenografía del lugar, los diálogos, los movimientos de los personajes, el fondo musical con close up en el protagonista, dotan de una gran plasticidad y sensación auditiva el desenvolvimiento como si estuviéramos presenciando un film cinematográfico. La letra de la canción en la voz de Sonia López infunde el ritmo interior en las emociones de El Guacho: De amor es mi negra pena/ de amor es que estoy llorando/valor le pido yo al cielo/y a Dios que me de consuelo/ si Judas mintió besando/ y Dios perdonó llorando/ qué puedo guardar en mi alma/ si no es mi dolor. Los planos narrativos se superponen: acciones, descripciones, diálogos y monólogos interiores otorgan al relato un dinamismo de fragmentación, no de ruptura, sino de fusión donde cada elemento funciona como soporte de los demás. El encuentro de miradas del Botas y el Guacho crean la tensión del discurso homoerótico latente. Con el transcurrir de las horas la narración va graduando la excitación con el roce de piernas, el consumo de alcohol; así como la angustia del deseo convertido en tormento ante la expectativa de ser señalado como "puto", "joto", "maricón", los motes más humillantes que puede sufrir un hombre en su masculinidad. En la segunda parte cambia la voz narrativa y desaparece la fragmentación: al día siguiente, el narrador-personaje trata de concentrarse en la pelota que corre en la cancha, para no perderla de vista. Al término del juego ganado, mientras se desvisten, las miradas afiebradas del Botas y el Guacho confirman la mutua atracción rotunda e irremediable. En el tercer capitulo, en un mísero burdel se reúnen los amigos para celebrar la victoria y son atendidos por Félix, un joven rubio que bien podría ser mujer por su delicada figura y facciones. Como bien señala Diana Palaversich:

El momento clave del cuento ocurre cuando a la mesa de los soldados se acerca un joven mesero. Los amigos manosean a Félix y literalmente se comunican entre sí a través del cuerpo afeminado del mesero. Sin embargo, la participación colectiva en este acto, esencialmente homosocial, les protege del estigma ya que todo el grupo manosea al otro hombre para humillarlo y burlarse de él. (143-144)

En el momento en que el Guacho toquetea al mesero, el Cuervo descubre la excitación del primero y: "con una expresión de triunfo, dijo casi gritando: 'miren jes puto!, ¡tiene la verga bien parada!', y el Rengo 'ora sí ya se supo, pinche culero' (Zapata, 40) Lo que equivale, según Mario Muñoz, a: "una condenación definitiva, pues significa la marginación y el descrédito completo; es decir, la muerte civil que el Guacho tanto temía." (30) El final trágico lo anuncia un disparo que proviene del baño. La historia del relato y el dramático desenlace hace evidente que al hombre en 
algunas comunidades le es prohibido alejarse del rol al que está sujeto, a consecuencia de vivir en el peor de los oprobios. El tratamiento psicológico que Zapata imprime en el relato, realza la fuerza del discurso homoerótico, tanto a nivel individual como colectivo y sus repercusiones en sociedades cerradas como pueden ser las militares. Con el suicidio, el Guacho, tratando de salvaguardar su honor de hombre macho, pone punto final a la negra pena de su amor.

Aunque 1981 es el año en que se inicia la era del sida, es hasta 1986 que el virus que propaga la enfermedad recibe el nombre de VIH (virus de inmunodeficiencia humana). En 1985, el famoso actor Rock Hudson declaró que padecía VIH. El caso conmocionó al mundo y repercutió de inmediato. Se hizo pública la magnitud de la pandemia. Las reglas del juego cambiaron hacia dentro y fuera de la comunidad gay. La paranoia, el miedo y el terror se apoderaron de grupos de homosexuales, ya que hasta ese momento se difundía que era una enfermedad entre gays y podía ser contagiada por cualquier medio. Fundamentalistas de diversas religiones veían al sida como castigo divino, y la sociedad en general tomó distancia. El sida y la homosexualidad pasaron a ser parte de la vida cotidiana propiciada por los medios de comunicación, y el resultado fue hacer visible de manera definitiva una forma de relacionarse afectiva y eróticamente diferente al binomio hombre-mujer. Ya en 1995, el gobierno de los Países Bajos encargó a una comisión parlamentaria investigar la posibilidad de establecer el matrimonio entre personas del mismo sexo, y en muchos países el tema gay comenzó a ser visto como parte de la agenda legislativa y política.

En los años noventa, en Estados Unidos y en Europa, la propagación de los estudios críticos sobre la temática gay es explosiva, ya sea desde un enfoque científico, social, antropológico o literario. La industria cinematográfica no se queda atrás y, en 1993, se exhibe la película Philadelphia, cuyo argumento principal es la enfermedad del sida. La academia de la artes le otorga dos premios Oscar, uno de ellos a Tom Hanks, como mejor actor, por su participación en la película como el protagonista infectado de sida.

En México la situación es diferente: proliferan las discotecas y se da una masificación del personaje gay, debido en gran parte a los modernos medios de transporte urbano como es el metro, lo que permite una mayor confluencia y posibilidad de acceso a lugares que antes eran remotos; el espacio elegido es la Zona Rosa. En el aspecto político, el panorama también toma nuevos matices con la creciente pérdida, para el PRI, de credibilidad y de escaños y puestos públicos de gran importancia, como las gubernaturas estatales. Los grupos de activistas trabajan sobre todo en demandas para la lucha en contra del sida y comprometen al gobierno a la implementación de amplias campañas de difusión.

En cuanto al panorama de la literatura en Hispanoamérica, la novela se convierte en el verdadero negocio de las editoriales, sobre todo trasnacionales, que promueven premios internacionales, relegando al cuento mas no su cultivo. El escritor peruano Jaime Bayly convierte en verdaderos best sellers sus novelas de temática gay: 
No se lo digas a nadie (1994), Fue ayer y ya no me acuerdo (1995), y La noche es virgen (1997). También en 1997 se publica la excelente novela Plata quemada, del gran escritor argentino Ricardo Piglia, que es llevada al cine con gran éxito, al igual que la primera novela de Bayly. Lo mismo ocurre con la autobiografía póstuma de Reinaldo Arenas, Antes que anochezca (1992). La película con el mismo nombre y basada en el libro de Arenas es protagonizada por Johnny Depp y Javier Bardem, quien es nominado al premio Oscar, en la categoría de mejor actor. La película precursora de gran impacto a nivel internacional fue Fresa y chocolate (1994), basada en el relato del cubano Senel Paz: El lobo, el bosque y el hombre nuevo (1991), ganador del premio Juan Rulfo.

En el año de 1996 surgen dos grupos literarios de capital importancia: en México, la conocida generación del Crack, representada principalmente por Jorge Volpi, Ignacio Padilla y Eloy Urroz; en Latinoamérica, McOndo (en alusión a Macondo, el pueblo imaginario de Cien años de soledad de García Márquez, y a McDonald`s), para enfatizar lo híbrido de la cultura del continente. Con el mismo nombre, $\mathrm{McOn}$ do (1996), titulan los recopiladores Alberto Fuguet y Sergio Gómez, el libro que reúne 17 relatos de jóvenes escritores de diez países, dos de ellos de temática gay: "Señales captadas en el corazón de una fiesta", del argentino Rodrigo Fresán, y "Extrañando a Diego", de Jaime Bayly. La situación en México de la literatura de temática gay es de una gran pobreza al respecto. En el género de la novela sólo se da el registro de las obras de Alberto Castillo (Letargo de Bahía, 1992), y de Gerardo Guiza Lemus (Quizás no entendí, 1997). La novela de mayor importancia es Salón de belleza (1994), de Mario Bellatín. En la cuentística se publican: "El alimento del artista" (1991), de Enrique Serna; "Sólo era un juego" (1996), de Víctor Rejón; "El último vacío" (1996) y "Nomás no me quiten lo poquito que traigo" (1999), de Eduardo Antonio Parra. En esta década destacan: De amores marginales (1996), una recopilación de Mario Muñoz de cuentos de temática gay, con un prólogo que hace las veces de ensayo crítico sobre la literatura del tema, y La novela mexicana entre el petróleo, la homosexualidad y la política (1997), de Luis Mario Schneider, en la que el investigador pasa breve revista del catálogo historiográfico de la novelística gay en México. Por lo que consideramos a estos dos académicos los pioneros en los estudios críticos de la literatura gay en México. Cabe mencionar también la importancia de los artículos de Carlos Monsiváis sobre la homosexualidad en México: "El mundo soslayado. Donde se mezclan la confesión y la proclama"; "Los gays en México: la fundación, la ampliación, la consolidación del ghetto"; "Los iguales, los semejantes, los (hasta hace un minuto) perfectos desconocidos (A cien años de la Redada de los 41)"; y, el "Prólogo" a la novela Jacinto de Jesús (2001), de Hugo Villalobos.

En el libro mencionado de Mario Muñoz aparece el relato de Víctor Rejón, "Sólo era un juego", que desde las primeras líneas el ambiente dramático se apodera del texto. El narrador-testigo se refiere a Leobardo, quien se encuentra postrado en una cama de hospital: "Las ojeras hacen más profundas las cuencas que contrastan con 
la palidez de los pómulos. Parece un títere abandonado en el fondo del baúl y no un joven de veinte años." (Rejón, 113) En el siguiente párrafo, la voz narrativa cambia su focalización y el tiempo histórico para dar paso a la analepsis dando cuenta del oficio de prostitución que ejercía Leobardo, cuando dos años antes sube al automóvil de una mujer de más de cincuenta años que lo lleva a su domicilio, ubicado en una de las zonas más lujosas de la ciudad de México, las Lomas de Chapultepec. Los encuentros eróticos entre la mujer y el joven se repiten cada semana durante varios meses. El tiempo sigue en retroceso, dos años atrás, cuando Leobardo y el narrador se mudan a la colonia Roma. Aquí detalla la relación con un anciano que lo abordó en su automóvil, conducido por un chofer vestido de uniforme. El ambiente de la casa del hombre mayor refleja por un lado, la ostentación, y por otro los íconos de los artistas del cine mexicano, cuyos retratos se encuentran adosados a las paredes de los pasillos: María Félix, Pedro Armendáriz, Dolores del Río, y Arturo de Córdova. Al tiempo que el proyector pone en movimiento a Pedro Armendáriz en "La Perla", el anciano se despoja de sus ropas para quedar en brasier y pantaletas con orillas de encaje. Sin enjuiciar ni denotar lo grotesco de la escena, el narrador describe el placer y el éxtasis de la culminación sexual. El tiempo sigue su marcha en el pasado, cuando Leobardo y el narrador llevaban un año de vivir en la ciudad de México. Leobardo de catorce años, sin prejuicios y con gran facilidad adopta como modus vivendi la prostitución. El primer cliente lo encuentra en las calles de Puebla y Valladolid. En la casa del hombre maduro se leen los títulos de los libros apostados en las repisas: La confusión de los sentimientos, El pozo de la soledad, De repente en el verano, y El vampiro de la colonia Roma, una referencia que hace obvia la similitud que el relato guarda con la novela de Luis Zapata, que al igual que Adonis, su protagonista, Leobardo, una vez descubierto el homoerotismo como forma de ganarse la vida, frecuenta las calles de Hamburgo, Amberes o Copenhague, enclavadas en la Zona Rosa. Con el mismo recurso narratológico llegamos al tiempo en que ambos amigos terminan la primaria en su pueblo. La escena es la estereotipada imagen del grupo de los casi adolescentes jugando en el río. Sin toqueteos o caricias previas Leobardo, excitado al ver cruzarse una pareja de burros, penetra con fuerza a uno de sus compañeros. El acto es visto por su padre, quien desde ese momento lo desconoce como hijo, lo que da pie a que Leobardo y su amigo, narrador-testigo de la historia, abandonen el pueblo.

El homosexual nacido en la provincia no tenía otra alternativa que huir a la gran urbe, de suerte que la ciudad de México es también otra ciudad para el homosexual que busca lugares para sus encuentros. Estos espacios son el ghetto de los marginados. Los homosexuales han vivido en un submundo, en una ciudad alterna, bajo las sombras de la noche propiciatoria; recorren calles, se apuestan en las esquinas, en las bancas de las plazas y jardines, se ocultan en la oscuridad de los cines, de los clubes prohibidos y muestran su desnudez en los baños de vapor. (Gutiérrez, 282) 
La última analepsis tiene lugar cuando Leobardo y el narrador-testigo y protagonista, en la época del primer año de primaria, se relacionan, por única ocasión, sexualmente. Aquí termina la retrospección, y en la misma voz narrativa leemos el final del relato:

Leobardo debe estar buscando en el recuerdo cuál de tantas parejas que ha tenido pudo haberlo contagiado, aunque, en realidad, me ha dicho, ya no le importa. Hace varios meses le dijeron que no tiene curación. Únicamente hay que esperar que un día cierre los ojos y al abrirlos se encuentre en otro lugar, en otro mundo. (Rejón, 120)

El cuento no sólo presenta una de las múltiples facetas de la vida gay, en este caso la prostitución, sino que es el primero en presentar y, hasta en cierta forma, documentar la propagación del sida a través de las prácticas homoeróticas. Como bien señala Palaversich: "Creo que es precisamente en el campo literario de América Latina donde se presenta una visión más realista de las relaciones homosexuales." (143) El título "Sólo era un juego", alude irónicamente al drama que día tras día viven jóvenes gays de provincia, que llegan a la gran capital sin expectaciones, y caen en las garras de la prostitución y en la vulnerabilidad misma de este tipo de vida.

El nuevo siglo arroja nuevas y, por qué no decirlo, luminosas luces para los gays del mundo occidental. Las luchas de más de treinta años, si consideramos la rebelión de Stonwall en 1969 como el inicio de la defensa de los derechos gays, finalmente cosechan sus frutos, entre otros muchos es el reconocimiento jurídico del matrimonio entre personas del mismo sexo en países como Holanda (2001), Bélgica (2003), España (2005), Canadá (2005), Sudáfrica (2006), Noruega (2009), Suecia (2009), Portugal, Islandia, Argentina y la ciudad de México en 2010. De la visibilidad se pasa a la legitimación, del silencio a la legislación, del señalamiento al respeto y a la tolerancia, del oprobio a la dignidad, del ghetto a la integración. Pero también hay que decir que las leyes no cambian la forma de pensar de las personas, de ahí que todavía la gran mayoría de la comunidad gay se presente a los ojos de la sociedad de manera desapercibida. Son los jóvenes de las grandes urbes quienes más han capitalizado estas victorias y sin enfado se congregan en bares, discotecas, playas, pasean de la mano o abrazados por las calles. Y el mercado ha encontrado un verdadero filón de oro en el extendido consumo gay: proliferan marcas de ropa exclusiva, destinos turísticos, cruceros, etc. Un comercio que deja ganancias multimillonarias.

El panorama literario del continente latinoamericano es muy diferente, atrás quedó el Boom de los escritores ahora consagrados. El nuevo mercado impone sus reglas, y ahora impera la obra de autor sin importar su nacionalidad. Ya no se busca desentrañar la identidad regional o nacional; lo inmediato, lo personal, lo íntimo y 
hasta lo circunstancial, como es el caso del narcotráfico, se convierten en la argumentación de la nueva narrativa condimentada en muchas de las veces con el hiperrealismo de la época. Esto no quiere decir que no se siga incursionando en la novela histórica, la policial, la gótica, la fantástica, la psicológica, la sentimental y la de tesis. Aún es muy temprano para categorizar y enjuiciar una obra que está en el proceso de desarrollo. En cuanto al tema que nos compete, en México, en la novelística, sólo aparecen Jacinto de Jesús (2001), de Hugo Villalobos, Toda esa gran verdad (2006), de Eduardo Montagner, Fruta verde (2006), de Enrique Serna, Los mártires del "Freeway" (2006), de Carlos Martín Briceño, y Temporada de caza para el león negro (2009), de Tryno Maldonado. En el cuento hay mayor profusión, crece la lista de autores, en donde se encuentran, entre otros: Ana Clavel, Will Rodríguez, Iris García, Nadia Villafuerte, Manuel Fuentes Cucurachi, Mario Heredia, Julio César Toledo, Luis Martín Ulloa, Iván Partida y Jesús de León.

Ignacio Padilla, ganador de numerosos premios literarios nacionales e internacionales, autor de ya una vasta e importante obra, y a quien la revista francesa Lire lo considera entre los cincuenta narradores más importantes para el siglo XXI, en 2008 se sumó a la lista de sus galardones el Premio Juan Rulfo-Radio Francia, por el cuento "Anacrónicos", que aquí nos ocupa. A lo largo de este trabajo se ha hecho un recorrido, desde los inicios de la mitad del siglo pasado por el cuento de temática homoerótica, atendiendo a la historiografía literaria y considerando el contexto de la evolución del gay dentro y fuera de la ficción. El cuento de Padilla, que es el último de este análisis, bien podría ser enlistado en los primeros por el ambiente histórico en el que se desarrolla. El texto, que es uno de los más extensos, se ajusta a la tesis de Ricardo Piglia: "Un relato visible esconde un relato secreto, narrado de un modo elíptico y fragmentario." (106) La narración inicia en el instante en que un grupo de ancianos combatientes de la batalla del Zurco, acaecida hace más de treinta años, se aprestan a la conmemoración anual cuando son sorprendidos por el suicidio de uno de los correligionarios: el alférez Joaquín Bautista, quien rayaba en los setenta años. La estructura narrativa es compleja, en este punto la acción se detiene para construir la historia con recuerdos, testimonios, intrigas, rumores y la memoria colectiva del pueblo. La digresión es el recurso que utiliza para hacer avanzar la historia que se centra en la importancia del Regimiento Santa Engracia y la celebración de la única batalla ganada en la guerra que perdieron. Se detalla paso a paso cómo se lleva año tras año el festejo que culmina con la escenificación de la batalla del Zurco, para la que son contratados fuereños que representan al enemigo vencido. El relato alejado del historicismo dibuja dos tenues huellas de las que se puede inferir que se trata de la Guerra Cristera (1926-1929), por la alusión que se hace de los federalistas como los contrarios y las arengas del cura: "Cada tercer domingo del año y cada día por la 
tarde desde un mes antes de conmemorarse la histórica contienda." (Padilla, 29) ${ }^{1}$ El secreto aparente de la historia tiene capital interés para el organizador de las reuniones y de la conmemoración, el capitán Nicolás Margules, quien después de encontrar el cadáver del alférez Bautista y cerrarle los ojos con un dulce ademán y agradecido de que nadie haya sido testigo de su debilidad, voltea la casa de arriba abajo en busca de una caja de guardar tabaco, en la que se supone el difunto conservaba documentos que revelaban el asesinato por la espalda del general Iruegas a manos de uno de los suyos y no del ejército federalista; hecho que con los años se había convertido en escarnio para los veteranos, que al tiempo que desfilaban por la calle principal del pueblo eran seguidos con gritos que salían escondidos detrás de las ventanas. Después de la larga digresión en la que conviven pasado y presente, elipsis y fragmentación, la acción se retoma en el momento que se disponen los funerales de gran honra para el alférez Bautista. Con tal pretexto, los viejos combatientes organizan un fastuoso "entierro militar como no se había visto desde los tiempos del frío. Allí estarían todos, ataviados como húsares, cargando de seis en seis el baúl abanderado del honorable Joaquín Bautista." (Padilla, 32) Aquí se presenta de manera clara el nostálgico homenaje que Ignacio Padilla hace al realismo mágico de García Márquez. Es inevitable la asociación del Regimiento Santa Engracia con el coronel Aureliano Buendía en Cien años de soledad, quien también se da un tiro en el pecho. En lo mítico es donde el eco es perfectamente audible. La secrecía es más notoria cuando, un año antes de su suicido, el alférez Joaquín Bautista fracturó su relación con los demás veteranos al enterarse, según contaba una sobrina del difunto, que habían acuchillado a un joven que venía a representar a los federalistas. El narrador recuerda que se trataba de un joven de no más de veinte años, de belleza extraordinaria, a quien sus compañeros rendían admiración por su hermosura. El peligro que representaba su competencia para los jóvenes del pueblo la querían contrarrestar criticando sus modales afeminados. Un día antes de la conmemoración de la batalla fue encontrado muerto en un burdel de un pueblo vecino, apuñalado con saña.

Muchos años después, en la capital, el narrador testigo recuerda el encuentro con Carlos Lagunas, sobrino nieto del alférez Joaquín Bautista, quien a su vez le cuenta que diez años antes había ido al pueblo, y al entrar a la casa del tío abuelo se dirigió al cuarto donde había muerto y, por instinto, su mirada se detuvo en el lugar donde había estado la cama. De la duela alzó una placa de madera y extrajo la fa-

${ }^{1}$ Actualmente en pueblos en que se llevó a cabo la conflagración cristera, como es el caso de San Julián, Jalisco, todavía se reúnen periódicamente integrantes de la Liga Nacional de Defensa Religiosa, fundada en 1925, y en el mes de marzo de cada año celebran con una cabalgata una de las derrotas infringidas a los federalistas. 
mosa caja de guardar tabaco. En lugar de encontrar las pruebas que incriminaban a los veteranos del Regimiento Santa Engracia en la muerte del general Iruegas, se encontraban, atadas con las cintas tricolores que habían decorado su uniforme en la batalla del Zurco, las cartas de amor que el sargento acuchillado había escrito al alférez Joaquín Bautista. Para todas las preguntas que requerían respuesta, el narrador da fin a la historia con las palabras: "Lo único cierto era el silencio." (Padilla, 34)

Ignacio Padilla nos enfrenta a un relato que requiere la participación activa del lector, cambia las reglas de las estructuras narrativas convencionales y guarda con celo la otra historia, como lo postula Piglia: "El cuento se construye para hacer aparecer artificialmente algo que estaba oculto. Reproduce la búsqueda siempre renovada de una experiencia única que nos permita ver, bajo la superficie opaca de la vida, una verdad secreta." (111) Y qué verdad más secreta entre hombres anacrónicos, héroes de una batalla mítica, que el deseo y la pasión por otro hombre donde no cabe ni siquiera la alusión a la caricia, menos al homoerotismo. De ahí que el silencio sea también la condena al silencio de la piel.

Alfonso Reyes, en su artículo "Teoría de la antología", señala que "toda antología es ya, de suyo, el resultado de un concepto sobre una historia literaria." (138) Tomando las palabras del gran escritor regiomontano, no nos queda más que cerrar este trabajo diciendo que el análisis panorámico del cuento gay nos lleva a una revaloración no sólo del género del cuento, sino también a la revisión de la evolución y construcción del personaje gay dentro de los contextos políticos, culturales y sociales, todo lo cual da como resultado un complejo concepto de la historia literaria del discurso homoerótico en el relato mexicano.

\section{BIBLIOGRAFÍA}

BARBACHANO Ponce, Miguel.

1964 El diario de José Toledo. México: Premiá. La red de Jonás.

BALDERSTON, Daniel.

1997 Sex and Sexuality in Latin America. USA: New York University Press.

BATAILLE, George.

2008 El erotismo. México: Tusquets.

FERRETIS, Jorge.

1952 "Los machos cabríos", en El coronel que asesinó un palomo y otros cuentos. México: FCE.

FOUCAULT, Michel.

1996 "Prefacio a la transgresión", en De lenguaje y literatura. Barcelona: Paidós.

GONZÁlEZ DE ALBA, Luis.

1981 "El vino de los bravos", en El vino de los bravos, México: Katún. 
GUTIÉRREZ, León Guillermo.

2003 "El silencio de los amores marginales", La Jornada Semanal, $\mathrm{n}^{\circ}$ 410, México.

2009 "La ciudad y el cuerpo en la novela mexicana de temática homosexual", Anales de Literatura Hispanoamericana, vol. 38, pp.

HERNÁNDEZ VIVEROS, Raúl.

1982 "Respiración artificial”, en El secuestro. Xalapa: Amate. LÓPEZ PÁEZ, Jorge.

1980 "Doña Herlinda y su hijo", Sábado, suplemento cultural del periódico Unomásuno, México.

MELO, Juan Vicente.

1962 "Los amigos", en Los muros enemigos. Xalapa: Universidad Veracruzana.

MonsivÁIs, Carlos.

1998 "El mundo soslayado. Donde se mezclan la confesión y la proclama", en La estatua de sal. México: CNCA.

2001 "Los iguales, los semejantes, los (hasta hace un minuto) perfectos desconocidos (A cien años de la Redada de los 41)", Debate feminista, vol. 24.

2001 "Prólogo", en Jacinto de Jesús, México: Fontamara.

2002 "Los gays en México: la fundación, la ampliación, la consolidación del ghetto", Debate feminista, vol. 26.

MUÑOZ, Mario.

1996 "Prólogo", en De amores marginales. Xalapa: Universidad Veracruzana.

PADILLA, Ignacio.

2009 "Los anacrónicos" (Premio Juan Rulfo-Radio Francia Internacional 2008), Revista de la Universidad de México, Nueva Época, $n^{\circ}$ 61, marzo.

PALAVERSiCH, Diana.

2005 De Macondo a McOndo. Senderos de la postmodernidad latinoamericana. México: Plaza y Valdés.

PALMA, Adrián.

2007 Locas, maricones, mayates, hombres, homosexuales, gays: apuntes históricos de la identidad y relaciones de género en varones con sexualidad del mismo sexo en el México moderno. (Tesis de Licenciado en Sociología). México: UNAM.

PELlicer, Carlos.

1941 Recinto y otras imágenes. México: FCE.

PIGLIA, Ricardo.

2001 Formas breves. Barcelona: Anagrama. 
PLAZA, Dolores.

1982 “Todos somos vecinos”, en El libro de los deseos. México: Ediciones Negro Sol.

RAMOS, Luis Arturo.

1979 "Siete veces el sueño", en Del tiempo y otros lugares. Xalapa: Amate.

REJÓN, Víctor.

1996 "Sólo era un juego", en De amores marginales. Mario Muñoz REYES, Alfonso. (comp.). Xalapa: Universidad Veracruzana.

1962 "Teoría de la antología", en Obras completas, vol. 14. México: FCE.

RODRÍGUEZ, Antoine.

2005 "El joto decente se casa. Normas y margen en 'Doña Herlinda y su hijo' de Jaime Humberto Hermosillo", Razón y palabra. Primera Revista Electrónica en América Latina Especializada en Comunicación.

SAMPERIO, Guillermo.

1978 "Los zapatos de la princesa", en Lenin en el futbol. México: Grijalbo.

SCHNEIDER, Luis Mario.

1997 La novela mexicana entre el petróleo, la homosexualidad y la politica. México: Nueva Imagen.

ZAPATA, Luis.

1983 “De amor es mi negra pena”, en De amor es mi negra pena. México: Panfleto/Pantomima.

1979 Las aventuras, desventuras y sueños de Adonis García, el vampiro de la colonia Roma. México: Grijalbo.

ZuBIAURRE, María Teresa.

2000 El espacio en la novela realista. México: FCE. 